\title{
Engineering the Human Microbiome, A Natural Double-Barreled Approach Towards Solving both our Current Antibiotic Resistance and Sepsis Problems
}

\author{
Martins $\mathrm{W}^{1}$, Mathias $\mathrm{J}^{1}$, Babenko $\mathrm{D}^{2}$ and Toleman $\mathrm{MA}^{1 *}$ \\ ${ }^{1}$ Cardiff University Medical school, Department of Immunology and Infection, The Heath hospital, UK \\ ${ }^{2}$ Karaganda Medical University, Kazakhstan
}

*Corresponding author: Toleman MA, Cardiff University Medical school, Department of Immunology and Infection, The Heath hospital, Cardiff, UK.

To Cite This Article: Martins W, Mathias J, Babenko D, Toleman MA, Engineering the Human Microbiome, A Natural Double-Barreled Approach Towards Solving both our Current Antibiotic Resistance and Sepsis Problems. Am J Biomed Sci \& Res. 2020 - 11(3). AJBSR.MS.ID.001632.

DOI: 10.34297/AJBSR.2020.11.001632.

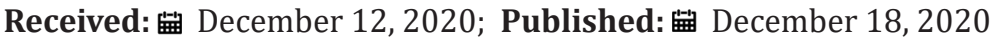

\section{Opinion}

Many of the bacteria that cause life-threatening infection live in very close association with us. Escherichia coli, for example causes $80 \%$ of common community associated urinary tract infections and is also the main cause of serious (blood-stream) infection throughout Europe [1,2]. However, E. coli routinely lives as a commensal organism in our gut. In fact, the main source of infection is the human gut. The likely hood of developing one of these infections is dependent on several factors with age playing a pivotal role [3]. Typically, the infection rate increases dramatically with age with peaks in the very young ( $<1$ year-old) and the very old (>70yrs). Another key factor is the type of E. coli strain that an individual carries in the gut since the species E. coli is composed of pathogenic and non-pathogenic strains. This means that an individual carrying a pathogenic strain is considerably more likely to develop infection than one carrying a non-virulent $E$. coli strain [4]. Similarly, high carriage of antibiotic resistant strains in the gut is much more likely to lead to an infection that is difficult to treat [5].

Antibiotic resistance in bacteria commonly carried in the human gut such as E. coli and Klebsiella pneumoniae has dramatically increased in importance since 2000 [6]. At that time within the UK, much of Europe and North America resistance to commonly used oral antibiotics such as ciprofloxacin was low. Resistance to commonly used parenteral antibiotics such as 3rd generation cephalosporin antibiotics was also low [6]. However, in the following few years the resistance rate climbed rapidly. The major resistance mechanism responsible for this rise was an enzyme called CTX-M-15 that gave resistance to the penicillin, monobactam, and cephalosporin classes of the ß-lactam family of antibiotics (c. $50 \%$ of all antibiotics) [7]. Its gene blaCTX-M-15 was first isolated in several enteric pathogens including $E$. coli in New Delhi, India in 2000 [8]. Later publications indicated that it was widespread across India in 2,000 causing resistance rates c. $60 \%$ in E. coli and K. pneumoniae in several geographically distinct institutions $[9,10]$. Importantly, the blaCTX-M-15 gene was closely associated with other resistance mechanisms giving resistance to ciprofloxacin, trimethoprim and sulphonamides making many of these infections multidrug resistant. Furthermore, the close association with the ß-lactamase OXA- 1 in these isolates rendered many of them additionally resistant to ß-lactam inhibitor combinations such as amoxicillin-clavulanic acid and piperacillin-tazobactam [11]. This put heavy pressure within India on the last useful class of ß-lactam antibiotic, the carbapenem class. Unfortunately, in 2008 we saw the rapid emergence and global dissemination from India of another new and powerful resistance mechanism, the New Delhi Metallob-lactamase (NDM-1) [12]. The combination of the blaNDM-1 resistance gene with several other resistance mechanisms in individual isolates brought the reality of untreatable pan-resistant bacterial strains and the growing realization that the antibiotic era was coming to an end [12].

One of the major factors in the rapid spread of these resistance mechanisms in S. Asia and then further afield is the huge problem 
with sanitation. Within India, many people do not have access to improved sanitation facilities such as those linked to sewers and septic systems [13]. This means that bacteria carrying resistance mechanisms are prevalent in drinking water, water-courses and rivers [14-16]. Contaminated water is used to irrigate crops and people are constantly re-infected with resistant bacteria with carriage rates of resistant bacteria in the general population being very high [17-19]. Therefore, the problem of antibiotic resistance in the hospitals is but the tip of the iceberg with most of the antibiotic resistance hidden within E. coli and K. pneumomiae bacterial strains carried in the human gut. The general population in India serves as a massive reservoir of antibiotic resistance where carriage of blaNDM is conservatively estimated at 100 million people and those carrying blaCTX-M-15 considerably higher [20].

The high carriage of the blaCTX-M-15 resistance mechanism in general in S. Asia meant that travellers to India staying 2 weeks were highly likely (88\%) to also become colonized and bring this resistance back to their own home countries as a hidden souvenir [21]. The close links between India and the UK and the mobility of the Indian population is highlighted by a study conducted in Birmingham, UK that recorded the carriage rate of $8 \%$ in peoples with European surnames and 23\% with Middle East or South Asian surnames [22]. South Asia is by no means the only continent where antibiotic resistance has emerged and spread. A similar situation happened with the carbapenemase KPC mostly in K. pneumoniae in the late 1990's in North America followed by regional and global spread [23]. However, the KPC epidemic was more closely linked to hospitals whereas the situation in S. Asia is more linked to the community and the general population. Similarly, other prevalent resistance mechanisms have emerged and spread from other countries [23].

In 2008, several publications highlighted the association of the blaCTX-M-15 resistance gene with a single E. coli sequence type (ST), ST131 [24-26]. This was a considerable concern since it belongs to the B2 pathogenic group of E. coli responsible for serious Extraintestinal Pathogenic E. coli (ExPEC) infections such as blood-stream infection. Subsequent research on this E. coli ST indicated that it was clonally disseminated worldwide with varying prevalence in different geographic regions [27]. Our recent research on historic isolates indicates that it was widespread in India in 2000. Its success has been attributed to the combination of chromosomal mutations giving rise to ciprofloxacin resistance, the acquisition of the fimH30 allele (a type 1 pilus adhesion variant characterized by high binding ability to human epithelial cells) and more recently blaCTX-M-15 and blaCTX-M-27 as well as other resistance genes [28].

A recent large UK study sought to understand the problem of antibiotic resistance in E. coli and found that the UK problem was associated with only a very few prevalent individual E. coli ST especially E. coli ST131 and to a much lesser extent E. coli ST38 [29]. This really is quite astounding when you consider that the $E$. coli species consists of $>10,000$ ST and the main problem in the UK and the US is essentially with only a single E. coli strain [28,29]. The study looked at bacteremias in UK hospitals and human gut carriage by assessing resistance rates in sewage and $>20,000$ feces samples. It revealed that the carriage rate in London was $17 \%$ and in other regions $8-10 \%$, meaning that there are probably 7,000,000 carriers of antibiotic resistant E. coli in the UK. Importantly, $64 \%$ of serious antibiotic resistant blood stream infections in the UK were caused by ESBL E. coli with the majority of these being ST131 harboring the blaCTX-M-15 gene. This study gave us the unique insight that the problem with serious infections due to antibiotic resistant strains in UK hospitals is a human carriage problem mostly due to a single prevalent $E$. coli strain in the community. Furthermore, the study informed us that the problem could easily be assessed by the study of bacterial strains in sewage.

The observation that antibiotic resistance is only associated with a small number of prevalent strains is not an unusual observation. Indeed, it seems that each resistance mechanism has its own "favorite" bacterial strain. Thus E. coli blaCTX-M-15 and blaCTX-M-27 are closely associated with E. coli ST131, blaCTX-M-14 is mostly associated with E. coli ST38 [29]. The carbapenemases blaNDM-1 and blaNDM-5 are closely associated with the prevalent E. coli strains ST101 and ST167 [15,18], respectively. This is not limited to E. coli only as we see the same with $K$. pneumoniae ST238 and its close association with the KPC carbapenemase [23]. The carbapenemase blaSPM-1 is mostly found in a single ST of Pseudomonas aeruginosa ST277 throughout Brazil [23], the blaVIM-2 metallo- $ß$-lactamase is found in a single strain of ST235 P. aeruginosa throughout Russia [30]. Neither is it limited to Gramnegative bacteria as we notice that the MRSA epidemic in the UK in the mid 2000's was primarily caused by two prevalent ST of Staphylococcus aureus ST22 and ST36 [31], nosocomial MRSA in the United States is caused by a single strain of ST5 Pulsed Field Gel Electrophoresis type (PFGE) USA 100 S. aureus and community associated MRSA in the US is caused by ST8 PFGE type USA300 S. aureus [32].

A very similar situation exists in the UK and further afield with virulent EXPEC E. coli strains. Serious ExPEC E. coli infection is also mostly caused by a very small number of strains with $>60 \%$ of all serious infection being caused by E. coli strains ST73, ST69, ST95, ST127 and ST131. In fact, in the UK not only have we experienced a year-on-year increase in antibiotic resistance but also the $E$. coli sepsis rate has more than doubled since 2009 [3]. Our recent UK sewage studies indicate that this is likely due to a higher gut carriage rate of virulent strains in the general population of the UK in the last decade [33]. 
The general lack of new antibiotics, the costs and difficulties associated with their discovery and licensing has led to a renaissance in bacteriophage therapy [34]. Bacteriophages are viruses that kill bacteria but are harmless to humans and animals and are ubiquitous in nature [35]. They were first used to treat animal and human diseases in the 1920's [35,36]. Though bacteriophage therapy has been used successfully to treat many different bacterial infections in former Soviet block countries for nearly a century. It fell out of use in the west because of the success of antibiotics [37]. This was associated with their broad spectrum of activity against numerous bacterial pathogens in comparison to the narrow spectrum of bacteriophage. Individual bacteriophages kill individual species of bacteria and normally a limited number of strains of an individual species though broader spectrum bacteriophages have also been identified [35]. Their narrow spectrum made them unreliable without prior testing of bacterial susceptibility and more suited to costly personalized medicine. That is personalized in terms of the pathogen rather than the patient [38]. However, the realization of the strain-specificity associated with most prevalent antibiotic resistant bacterial pathogens means that bacteriophage therapy is ideally suited to solve our current major bacterial problems. That is antibiotic resistance and rising sepsis rates.

The treatment of bacterial infection with bacteriophage was previously limited to just a few institutions notably the Eliava institute in Tblisi, The Hirszfeld Institute of Immunology and Experimental Therapy in Wroclaw, Poland [39], and the Queen Astrid hospital in Brussels [40]. However, the increasing number of untreatable infections has spawned their use in several other countries. In 2016, the first known person in the USA was treated with intravenous bacteriophage under the FDA emergency use authorization for an MDR Acinetobacter baumanii infection [41]. His recovery was almost immediate waking from a month-long coma. Further successful treatments led to the launch of the Centre for the Innovative Phage Applications and Therapeutics (IPATH) in June 18 at the UC San Diego College of Medicine. In 2017, an offshoot of the Eliava institute was set up in New Delhi pioneered by Pranav and Apurva Johri. Pranav himself was suffering with a long term prostrate infection caused by multiple pan-resistant bacteria and was treated in Tblisi. Inspired by his recovery he founded Vitalis phage therapy that treats people in India with bacteriophage from the Eliava institute [42]. Similarly, there have been several highprofile papers of the successful decolonization of individuals with multi-drug resistant bacteria with bacteriophage sourced from the Eliava institute $[43,44]$.

Bacteriophage are known to naturally control epidemics of pathogenic bacteria. This has been well described for Cholera in Dhaka, Bangladesh. The annual Cholera epidemics begin with the observation of increasing numbers of Vibrio cholera in environmental waters. This is followed by the epidemic in people
[45]. The epidemic fades as V. cholera specific bacteriophage subsequently increase in environmental waters and in people suffering with cholera. The whole process is rapid taking just a few weeks [45]. The knowledge of this, together with the observation of high carriage of pathogenic E. coli belonging to phylotype B2 in the UK such as ST131 and low carriage of this E. coli strain in Pakistan [17], Northern India [18] and the Qassim region of Saudi Arabia inspired us to look into the prevalence of bacteriophage capable of killing this strain in the different countries. We found that the prevalence of bacteriophage able to kill this strain was high in countries with low prevalence and vice versa [46], suggesting that epidemics of resistant strains such as ST131 could be manipulated by bacteriophage that specifically remove this strain by oral administration. There is also a clear precedent for oral administration of bacteriophage in that several bacterial pathogens found in food products are already controlled by bacteriophage additives licensed for food use [35]. Similarly, the Eliava institute has been using orally administered bacteriophage for nearly 100 years [47] and the US FDA have classified bacteriophage for food usage as "Generally regarded as Safe" [35].

Therefore, the application of a cocktail of bacteriophages to manipulate the human microbiome by selectively killing virulent and antibiotic resistant bacteria holds great promise. This approach minimizes many of the regulatory difficulties associated with the intravenous use of bacteriophages and is preventative rather than reactionary. The fact that bacteriophages multiply as they kill pathogens also means that it may have the capacity to change the carriage dynamics and drain the human reservoirs of pathogenic and antibiotic resistant bacteria.

\section{References}

1. Kraker MEA, Jarlier V, Monen JCM, Heuer OE, Van De Sande N, et al. (2013) The changing epidemiology of bacteraemias in Europe: trends from the European Antimicrobial Resistance Surveillance System. Clin Microbiol Infect 19(9): 860-868.

2. Laupland KB (2013) Incidence of bloodstream infection: a review of population-based studies. Clin Microbiol Infect 19(6): 492-500.

3. (2018) Laboratory surveillance of Escherichia coli bacteraemia in England, Wales, and Northern Ireland: 2018. Health Protection Report 13(37).

4. Dale AP, Woodford N (2015) Extra-intestinal pathogenic Escherichia coli (ExPEC): disease, carriage and clones. J Infect 71(6): 615-626.

5. Schwaber MJ, Carmeli Y (2007) Mortality and delay in effective therapy associated with extended-spectrum b-lactamase production in Enterobacteriaceae bacteraemia: a systematic review and meta-analysis. J Antimicrob Chemother 60(5): 913-920.

6. Livermore DM (2009) Has the era of untreatable infections arrived? Journal of Antimicrobial Chemotherapy 4(1): 29-36.

7. Nicolas Chanoine MH, Bertrand X, Madec JY (2014) Escherichia coli ST131, an intriguing clonal group. Clin Microbiol Rev 27(3): 543-574.

8. Karim A, Poirel L, Nagarajan S, Nordmann P (2001) Plasmid-mediated extended-spectrum $\beta$-lactamase (CTX-M-3 like) from India and gene association with insertion sequence ISEcp1. FEMS Microbiol. Lett. 201(2): 237-224. 
9. Mathai D, Rhomberg PR, Biedenbach DJ, Jones RN (2002) India Antimicrobial Resistance Study Group. Evaluation of the in vitro activity of six broad-spectrum beta-lactam antimicrobial agents tested against recent clinical isolates from India: a survey of ten medical center laboratories. Diagn Microbiol Infect Dis 44(4): 367-377.

10. Toleman MA, Biedenbach D, Jones RN, Walsh TR (2002) Molecular characterization of ß-lactamases from E. coli and Klebsiella pneumonia isolated from a multi-centre trial in India: Benchmark report from the Mystic program. Poster C2-1872, Interscience Conference on Antimicricrobial Agents and Chemotherapy.

11. Livermore DM, Day M, Cleary P, Hopkins KL, Toleman MA, et al (2019) OXA-1 $\beta$-lactamase and non-susceptibility to penicillin/ $\beta$-lactamase inhibitor combinations among ESBL-producing Escherichia coli. J Antimicrob Chemother 74(2): 326-333.

12. Kumarasamy KK, Toleman MA, Walsh TR, Bagaria J, Butt F, et al (2010) Emergence of a new antibiotic resistance mechanism in India, Pakistan and the UK: a molecular, biological, and epidemiological study. Lancet Infect Dis 10(9): 597-602.

13. https://www.economist.com/the-economist-explains/2017/09/24/ why-it-is-so-hard-to-fix-indias-sanitation.

14. Walsh TR, Weeks J, Livermore DM, Toleman MA (2011) Dissemination of NDM-1 positive bacteria in the New Delhi environment and its implications for human health: an environmental point prevalence study. Lancet Infect Dis 11(5): 355-362.

15. Toleman MA, Bugert JJ, Nizam SA (2015) Extensively drug-resistant New Delhi metallo- $\beta$-lactamase-encoding bacteria in the environment, Dhaka, Bangladesh, Emerg Infect Dis 1027-1030.

16. Talukdar PK, Rahman M, Nabi A, Islam Z, Hoque MM, et al (2013) Antimicrobial resistance, virulence factors and genetic diversity of Escherichia coli isolates from household water supply in Dhaka, Bangladesh. PLoS ONE 8(4): e61090.

17. Zahra R, Javeed S, Malala B, Babenko D, Toleman MA (2018) Analysis of Escherichia coli STs and resistance mechanisms in sewage from Islamabad, Pakistan indicates a difference in E. coli carriage types between South Asia and Europe. J Antimicrob Chemother 73(7): 17811785 .

18. Paul D, Babenko D, Toleman MA (2020) Human carriage of cefotaximeresistant Escherichia coli in North-East India: an analysis of STs and associated resistance mechanisms. J Antimicrob Chemother 75(1): 7276.

19. Perry JD, Naqvi SH, Mirza IA, Alizai SA, Hussain A, et al (2011) Prevalence of faecal carriage of Enterobacteriaceae with NDM-1 carbapenemase at military hospitals in Pakistan, and evaluation of two chromogenic media. J Antimicrob Chemother 66(10): 2288-2294.

20. Walsh TR, Toleman MA (2012) The emergence of pan-resistant Gramnegative pathogens merits a rapid global political response. J Antimicrob Chemother 67(1): 1-3.

21. Tängdén T, Cars O, Melhus A, Löwdin E (2010) Foreign travel is a major risk factor for colonization with Escherichia coli producing CTX-M-type extended-spectrum beta-lactamases: a prospective study with Swedish volunteers. Antimicrob Agents Chemother 54(9): 3564-3568.

22. Wickramasinghe NH, Xu L, Eustace A, Shabir S, Saluja T, et al (2012) High community faecal carriage rates of CTX-M ESBL-producing Escherichia coli in a specific population group in Birmingham, UK. J Antimicrob Chemother 67(5): 1108-1113.

23. Van Duin D, Doi Y (2017) The global epidemiology of carbapenemaseproducing Enterobacteriaceae. Virulence 8(4): 460-469.

24. Coque TM, Novais A, Carattoli A, Poirel L, Pitout J, et al (2008) Dissemination of clonally related Escherichia coli strains expressing extended-spectrum beta-lactamase CTX-M-15. Emerg Infect Dis 14(2): 195-200.
25. Nicolas-Chanoine MH, Blanco J, Leflon-Guibout V, Demarty R, Alonso $\mathrm{MP}$, et al (2008) Intercontinental emergence of Escherichia coli clone 025:H4-ST131 producing CTX-M-15. J Antimicrob Chemother 61(2): 273-281.

26. Clermont O, Lavollay M, Vimont S, Deschamps C, Forestier C, et al (2008) The CTX-M-15-producing Escherichia coli diffusing clone belongs to a highly virulent B2 phylogenetic subgroup. J Antimicrob Chemother 61(5): 1024-1028.

27. Nicolas-Chanoine MH, Bertrand X, Madec JY (2014) Escherichia coli ST131, an intriguing clonal group. Clin Microbiol Rev 27(3): 543-574.

28. Johnson JR, Porter S, Thuras P, Castanheira M (2017) The Pandemic H30 Subclone of Sequence Type 131 (ST131) as the Leading Cause of Multidrug-Resistant Escherichia coli Infections in the United States (2011-2012). Open Forum Infect Dis 4(2): ofx089.

29. Day MJ, Hopkins KL, Wareham DW, Toleman MA, Elviss N, et al (2019) Extended-spectrum $\beta$-lactamase-producing Escherichia coli in humanderived and food chain-derived samples from England, Wales, and Scotland: an epidemiological surveillance and typing study. Lancet Infect Dis 19(12): 1325-1335.

30. Edelstein MV, Skleenova EN, Shevchenko OV, D'souza JW, Tapalski DV, et al (2013) Spread of extensively resistant VIM-2-positive ST235 Pseudomonas aeruginosa in Belarus, Kazakhstan, and Russia: a longitudinal epidemiological and clinical study. Lancet Infect Dis 13(10): 867-876.

31. Enright MC, Day NP, Davies CE, Peacock SJ, Spratt BG (2000) Multilocus sequence typing for characterization of methicillin-resistant and methicillin-susceptible clones of Staphylococcus aureus. J Clin Microbiol 38(3):1008-1015.

32. King JM, Kulhankova K, Stach CS, Vu BG, Salgado-Pabón W (2016) Phenotypes and Virulence among Staphylococcus aureus USA100, USA200, USA300, USA400, and USA600 Clonal Lineages. mSphere 1(3): e00071-e00116.

33. Almusallam A, Babenko D, Toleman MA (2020) Analysis of Escherichia coli phylotypes and known sepsis causing sequence types in UK sewage reveals a direct link between sepsis rates and carriage of pathogenic sequence types in the community Mathias J. EMJ Microbiol \& Infect Dis 19(1): 27-28.

34. Abdelkader K, Gerstmans H, Saafan A, Dishisha T, Briers Y (2019) The Preclinical and Clinical Progress of Bacteriophages and Their Lytic Enzymes: The Parts are Easier than the Whole. Viruses. 11(2): 96.

35. Martins WMBS, Toleman MA, Gales AC (2020) Clinical utilization of bacteriophages: a new perspective to combat the antimicrobial resistance in Brazil. Braz J Infect Dis. 24(3): 239-246.

36. Nelson EJ, Harris JB, Morris JG, Calderwood SB, Camilli A (2009) Cholera transmission: the host, pathogen and bacteriophage dynamic. Nat Rev Microbiol 7(10): 693-702.

37. Wittebole X, Roock S, Opal SM (2014) A historical overview of bacteriophage therapy as an alternative to antibiotics for the treatment of bacterial pathogens. Virulence 5(1): 226-235.

38. Manohar P, Loh B, Athira S, Nachimuthu R, Hua X, et al (2020) Secondary Bacterial Infections During Pulmonary Viral Disease: Phage Therapeutics as Alternatives to Antibiotics? Front Microbiol 11: 1434.

39. Żaczek M, Weber-Dąbrowska B, Międzybrodzki R, Łusiak-Szelachowska M, Górski A (2020) Phage Therapy in Poland - a Centennial Journey to the First Ethically Approved Treatment Facility in Europe. Front Microbiol 11: 1056.

40. Djebara S, Maussen C, De Vos D, Merabishvili M, Damanet B et al (2019) Processing Phage Therapy Requests in a Brussels Military Hospital: Lessons Identified. Viruses. 11(3): 265. 
41. Schooley RT, Biswas B, Gill JJ, Hernandez-Morales A, Lancaster J, et a (2017) Development and Use of Personalized Bacteriophage-Based Therapeutic Cocktails to Treat a Patient with a Disseminated Resistant Acinetobacter baumannii Infection. Antimicrob Agents Chemother 61(10): e00954-e01017.

42. https://www.vitalisphagetherapy.com/

43. Corbellino M, Kieffer N, Kutateladze M, Balarjishvili N, Leshkasheli L, et al (2020) Eradication of a Multidrug-Resistant, Carbapenemase-Producing Klebsiella pneumoniae Isolate Following Oral and Intra-rectal Therapy With a Custom Made, Lytic Bacteriophage Preparation. Clin Infect Dis 70(9): 1998-2001.
44. Poirel L, Nordmann P, de la Rosa JMO, Kutateladze M, Gatermann S, et al. (2020) A phage-based decolonisation strategy against pan-resistant enterobacterial strains. Lancet Infect Dis 20(5): 525-526.

45. Faruque SM, Islam MJ, Ahmad QS, Faruque AS, Sack DA, et al (2005) Selflimiting nature of seasonal cholera epidemics: Role of host-mediated amplification of phage. Proc Natl Acad Sci USA 102(17): 6119-6124.

46. Mathias J Almusallam A, Babenko D, Toleman MA (2020) Bacteriophage control the prevalence of Escherichia coli ST131 in different countries. EMJ Microbiol Infect Dis 1(1): 18-19.

47. http://phage.ge/products/intesti-bacteriophage/ 